\title{
Albumin administration in the acutely ill: what is new and where next?
}

\author{
Jean-Louis Vincent ${ }^{1 *}$, James A Russell ${ }^{2}$, Matthias Jacob ${ }^{3}$, Greg Martin ${ }^{4}$, Bertrand Guidet ${ }^{5,6}$, Jan Wernerman ${ }^{7}$, \\ Ricard Ferrer Roca ${ }^{8}$, Stuart A McCluskey ${ }^{9}$ and Luciano Gattinoni ${ }^{10}$
}

\begin{abstract}
Albumin solutions have been used worldwide for the treatment of critically ill patients since they became commercially available in the 1940s. However, their use has become the subject of criticism and debate in more recent years. Importantly, all fluid solutions have potential benefits and drawbacks. Large multicenter randomized studies have provided valuable data regarding the safety of albumin solutions, and have begun to clarify which groups of patients are most likely to benefit from their use. However, many questions remain related to where exactly albumin fits within our fluid choices. Here, we briefly summarize some of the physiology and history of albumin use in intensive care before offering some evidence-based guidance for albumin use in critically ill patients.
\end{abstract}

\section{Introduction}

Albumen is doubtless one of the most important of the animal proximate principles.

\section{(Henry Ancell [1])}

Albumin solutions have been used worldwide for the treatment of critically ill patients since they became commercially available in the 1940s. However, driven largely by the results of a widely publicized metaanalysis in 1998 that reported increased mortality rates in patients who received albumin solutions [2], the role of albumin administration in critically ill patients became highly controversial. It is well known that albumin has multiple physiological effects [3], including regulation of colloid osmotic pressure (COP), binding and transportation of various substances (for example, drugs, hormones) within the blood, antioxidant properties, nitric oxide modulation and buffer capabilities, which may be of particular relevance in critically ill patients. It is also well established that low serum albumin levels, a common occurrence in critically ill patients, are associated with worse outcomes $[4,5]$. There would therefore seem to be a good rationale for use of albumin infusions in critically ill patients. However, albumin solutions also

\footnotetext{
* Correspondence: jlvincen@ulb.ac.be

'Department of Intensive Care, Erasme Hospital, Université libre de Bruxelles, route de Lennik 808, 1070 Brussels, Belgium

Full list of author information is available at the end of the article
}

have limitations, including high costs relative to possible alternatives, notably crystalloids, and potential (rare) risks of transmission of microorganisms, anticoagulant, and allergic effects [6-8]. Because there are no definitive randomized controlled trials (RCTs) demonstrating an outcome benefit of albumin in heterogeneous groups of critically ill patients, routine administration of albumin for fluid resuscitation is not warranted in all patients, but there is evidence to support its use in some patient populations.

The purpose of this article is not to review in detail the multiple functions and roles of albumin or the many comparative studies and meta-analyses that have now been performed, although we will briefly summarize this information to provide some context. Rather, we wish to provide some clear suggestions and guidance for albumin use based on the current available evidence and highlight important areas for future research.

\section{Some background \\ History}

Albumin was one of the first human proteins to be isolated and extracted from plasma for clinical use. First crystallized in 1934, a preparation was made available for clinical use in the 1940s [9,10]. Early successful use in multi-trauma and severely burned patients led to rapid expansion of the so-called human albumin program in the 
USA [11], and albumin use spread from the military setting to civilian hospitals and into regular use in operating and emergency rooms around the world. The first commercially available preparations of intravenous human albumin solution were developed using the cold alcohol fractionation technique created by Edwin Joseph Cohn $[9,11]$. Later developments and refinements in extraction and processing have resulted in increasingly pure solutions [12].

\section{Physiological properties}

Albumin is a natural plasma protein synthesized exclusively by the liver at a rate of 9 to $14 \mathrm{~g} /$ day in healthy individuals, with a median half-life of about 18 to 19 days (Figure 1) [9]. Albumin is catabolized in most organs of the body at a similar rate of about 9 to $14 \mathrm{~g} /$ day, by uptake into endocytotic vesicles on the endothelial surface $[9,13]$; the final breakdown products are amino acids [13].

Albumin has well-known effects on maintaining fluid balance, being responsible for 75 to $80 \%$ of COP in the basal physiological state $[9,10]$. In critically ill patients, particularly those with sepsis, the relationship between COP and the albumin concentration is complex, being influenced by altered permeability and increased transcapillary escape rates $[14,15]$. Moreover, improved understanding of the endothelial glyocalyx has altered our comprehension of the role of COP in fluid balance [16]. Numerous experimental studies have confirmed that the traditional understanding of an inwards-directed oncotic gradient between a protein-low interstitial space and a protein-rich plasma, as suggested by Ernest Starling more than 100 years ago, is not correct; indeed, the interstitial compartment has high protein concentrations. Nevertheless, there is a functional vascular barrier, created by the endothelial glycocalyx layer, a skeleton of glycoproteins, proteoglycans and glycosaminoglycans, and its

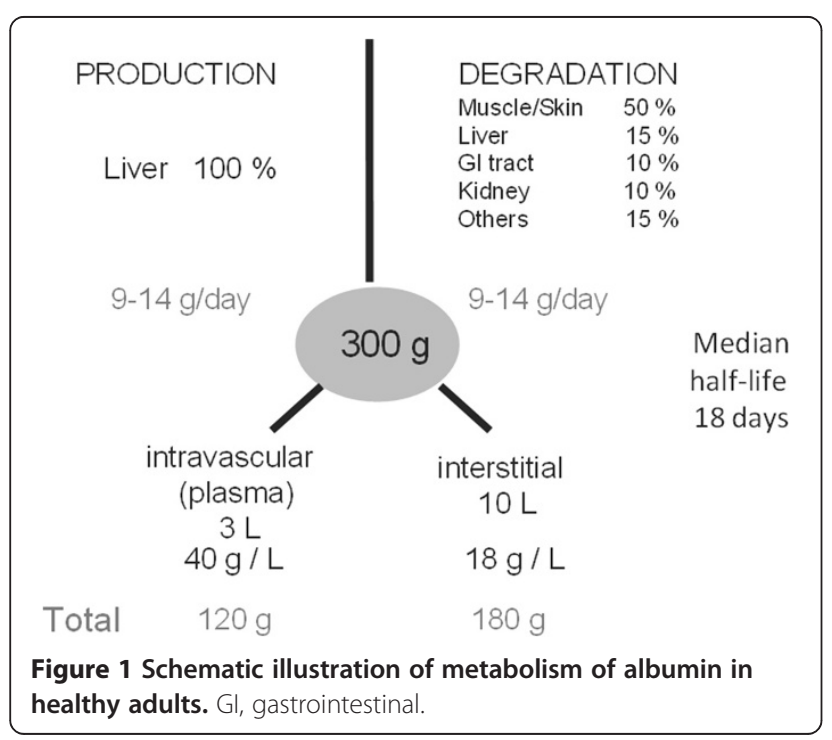

interaction with plasma constituents, including albumin, to form the endothelial surface layer, which is positioned on the luminal side of the endothelium with a thickness of up to $1 \mu \mathrm{m}$ in humans [16-19]. A small space, situated on the luminal side of the endothelium beneath this protein sponge, is permanently cleared of passing protein molecules by a protein-low resting flux through small breaks in the intercellular junction strands towards the tissues [18]. Accordingly, an inwardly-directed oncotic force, quantitatively opposite to the hydrostatically driven fluid filtration, develops exclusively across the small space beneath the glycocalyx and the protein-loaded endothelial surface layer (Figure 2).

Current understanding of optimal vascular barrier function in the high-pressure segment of the vascular system includes an intact glycocalyx combined with a minimum concentration of plasma proteins [20]. Although albumin is therefore a crucial part of the endothelial surface layer and infusing albumin may seem a reasonable suggestion to improve and maintain vascular barrier competence, experiments in isolated organs have shown that the endothelial surface layer appears to function well until the albumin concentration falls to a value as low as around $10 \mathrm{~g} / \mathrm{l}$ [21]. Hence, the major insult when the vascular barrier fails to function because of a severe acute illness is most probably not hypoalbuminemia, but a breakdown of the molecular structure of the endothelial glycocalyx because of hypervolemia or ischemia/reperfusion injury and other forms of systemic inflammation [22]. Nevertheless, below a certain threshold, artificial substitutes such as starches or gelatin are not sufficient to form an endothelial surface layer with a

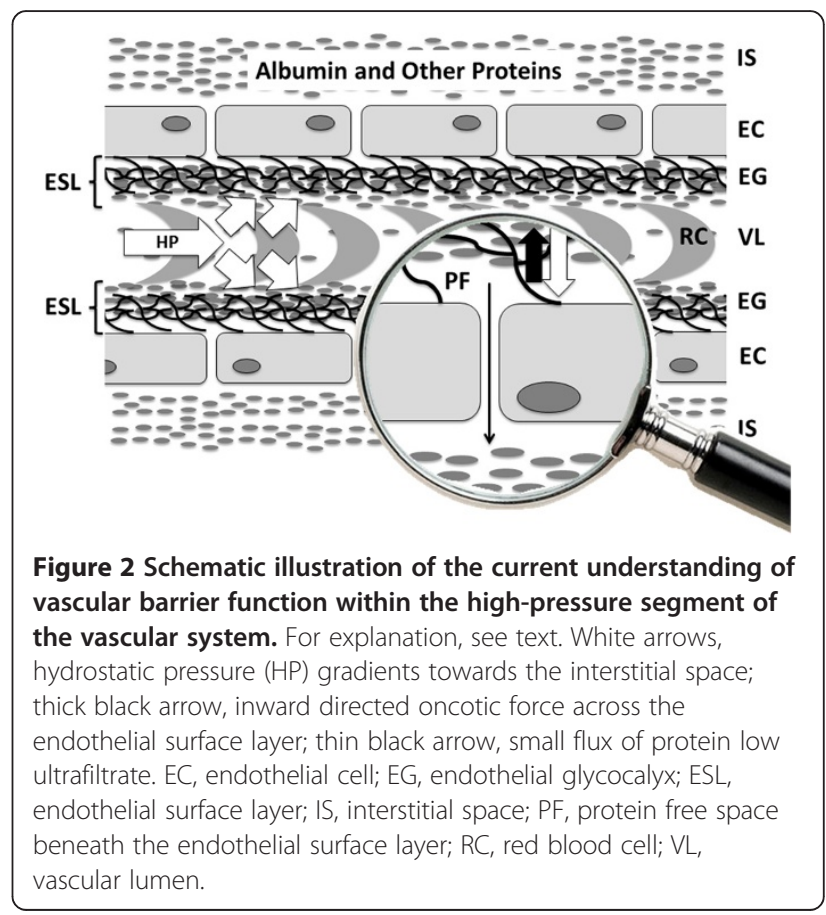


resistance against pressure-dependent fluid and protein outflow comparable with albumin $[21,23]$.

Albumin has many other properties in addition to its effects on intravascular volume, including transport and antioxidant activities, but their importance in health and disease are less well documented.

The antioxidant effects of albumin are, in brief, related to its ability to bind certain ligands, notably iron and copper, which reduces the availability of these compounds for pro-oxidant reactions, and are related to an exposed thiol group on the free cysteine residue, which acts as a free radical scavenger, able to interact with or trap reactive oxygen or nitrogen species, including nitric oxide, a key mediator in many conditions including sepsis [10,24-26].

In addition to the binding of iron and copper ions, albumin also transports multiple other endogenous and exogenous substances (Figure 3) [13]. Changes in albumin concentrations and structure during critical illness can therefore potentially have marked effects on normal homeostasis and metabolism and on drug delivery and efficacy $[10,27]$. In a systematic review, Ulldemolins and colleagues reported that protein binding of antibacterials, including ceftriaxone, ertapenem, teicoplanin, and aztreonam, was frequently decreased in critically ill patients with hypoalbuminemia, notably with increased volume of distribution and drug clearance [27]. These changes could result in suboptimal treatment, particularly for time-dependent antibiotics, and may necessitate dose adjustment.

The balance of acidic to basic residues on albumin makes it a weak acid in physiological concentrations [10,28], so that a decrease in albumin concentration increases the anion gap. This passively increases bicarbonate concentration, and is therefore associated with development of metabolic alkalosis.

Albumin also has anticoagulant effects similar to, but much less potent than, those of heparin, and inhibits platelet aggregation [29].

Finally, albumin can protect the microvasculature and mitigate increased vascular permeability via its antioxidant, anti-inflammatory effects, and anti-apoptotic effects [3].

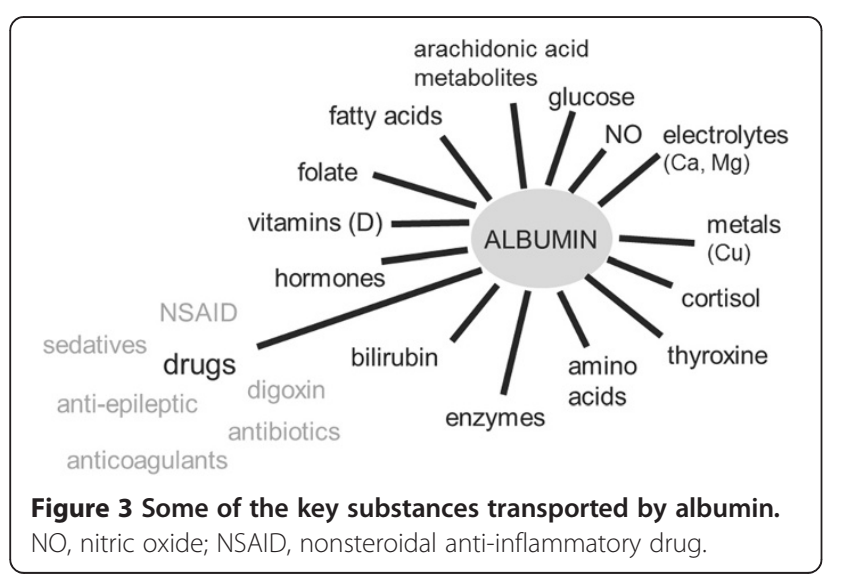

Clearly there is much about the physiologic effects of albumin that is not yet well understood [8]. These effects are probably altered in various disease states, particularly those associated with oxidant stress such as sepsis, but whether and how these changes are involved in the pathogenesis of these conditions requires further elucidation. Administration of exogenous albumin may help restore or provide additional antioxidant capacity, transport capabilities, and vascular barrier competence, which may account for some of the beneficial effects of albumin seen in specific patient populations, but it is difficult to differentiate these from albumin's effects on intravascular volume.

\section{Hypoalbuminemia}

Hypoalbuminemia (generally defined as a serum albumin concentration $\leq 30 \mathrm{~g} / \mathrm{l})[5,30]$ is very common in critically ill patients, the main reasons probably being increased albumin losses from bleeding and via the gastrointestinal tract [31], increased capillary permeability leading to a redistribution from the intravascular to the interstitial space (previously called third-spacing) [32], and dilution from intravenous fluid administration Moreover, in some patients - particularly older patients - baseline albumin levels may already be low as a result of poor nutritional status or altered liver function. Although animal models suggested that albumin synthesis may be reduced in critical illness [33], synthesis appears to be increased in critically ill humans [34].

Importantly, whatever the underlying mechanisms, hypoalbuminemia is associated with worse outcomes including increased complications [5,35-38] and reduced short-term [5,39-43] and longer-term [42,44] survival in critically ill patients. In a meta-analysis of 90 cohort studies that had evaluated hypoalbuminemia as a prognostic biomarker in acutely ill patients, each $10 \mathrm{~g} / \mathrm{l}$ decrease in serum albumin concentration was associated with a $137 \%$ increase in the odds of death, an $89 \%$ increase in morbidity, and a $71 \%$ increase in length of hospital stay [5]. There is therefore a clear association between the albumin level and the severity of the insult [45], but it remains uncertain whether the effect of hypoalbuminemia on outcome is a cause-effect relationship or whether hypoalbuminemia is rather a marker of serious disease.

\section{Early clinical trials}

For resuscitation in heterogeneous groups of critically ill patients

Although albumin solutions were first introduced in the 1940s, the first RCT of albumin administration was only published some 30 years later in 1975 (Table 1). This early RCT, conducted in just 16 patients undergoing abdominal aortic surgery, compared the effects of intraoperative use of albumin solution with those of a sodium-rich fluid 
during surgery and showed that albumin infusion led to less extracellular fluid expansion [46]. Other relatively small studies followed, so that by the time the Cochrane meta-analysis [2] was published in 1998 the average sample size of the 32 included studies was just 46 patients. Although the results of many studies take years to be published and to change clinical practice - if indeed they ever do - this Cochrane report influenced practice rapidly around the world, especially in the UK where use of albumin decreased by 40 to $45 \%$ in the 6 months after publication [47]. An Expert Working Party of the Committee on Safety of Medicines in the UK highlighted the thoughts of many in the medical community that there was an urgent need to conduct large multicenter RCTs to determine whether albumin administration did indeed worsen outcomes [48]. In 2004, the results of the Saline versus Albumin Fluid Evaluation (SAFE) RCT in almost 7,000 critically ill patients were published, showing that a $4 \%$ albumin solution was as safe as normal saline when used as a resuscitation fluid [49].

\section{For resuscitation in patients with sepsis}

Subgroup analysis of the SAFE study suggested there may be a benefit in patients with severe sepsis (35\% of whom had septic shock), with an adjusted odds ratio for death of 0.71 (95\% CI, 0.52 to $0.97 ; P=0.03$ ) for albumin compared with saline [54]. A subsequent meta-analysis that included 17 RCTs comparing albumin solutions with other fluids for fluid resuscitation in patients with sepsis reported that albumin use was associated with 
decreased mortality (odds ratio, $0.82 ; 95 \% \mathrm{CI}, 0.67$ to $1.0 ; P=0.047$ ) [58]. Guidelines currently suggest (grade $2 \mathrm{C}$ ) that albumin use should be considered as a resuscitation fluid in patients with severe sepsis, particularly if those patients are not responding to crystalloid infusion [59,60], based on data from the meta-analysis [58] and preliminary data from a multicenter study in France that suggested a nonsignificant reduction in mortality in patients with septic shock who received albumin [61].

\section{For resuscitation in patients with traumatic brain injury}

In the SAFE trial, patients with traumatic brain injury treated with albumin had worse outcomes than salinetreated patients [55]. Using pattern mixture modeling, the probable mechanism for the increased mortality appeared to be albumin-induced increases in intracranial pressure [63]. The hypotonic and hypooncotic nature of the albumin solution used may also have played a role [64].

\section{For albumin replacement in patients with hypoalbuminemia} The effects of increasing albumin concentrations by giving exogenous albumin have also been investigated in the critically ill. A meta-analysis of nine prospective controlled trials on correcting hypoalbuminemia in acutely ill patients suggested that complication rates were reduced in patients who achieved serum albumin concentrations $>30$ g/l after albumin administration [5]. However, in a subgroup analysis of the SAFE study in patients with hypoalbuminemia, using a cutoff value of $25 \mathrm{~g} / \mathrm{l}$ [4], there were no significant differences in outcomes in hypoalbuminemic patients and normoalbuminemic patients who received albumin. In a pilot RCT of 100 hypoalbuminemic critically ill patients who were randomized either to receive $300 \mathrm{ml}$ of $20 \%$ albumin solution on the first day and then $200 \mathrm{ml} /$ day if the serum albumin concentration remained $<30 \mathrm{~g} / \mathrm{dl}$ or to receive no albumin, Dubois and colleagues reported that organ function (as assessed by change in the Sequential Organ Failure Assessment score) improved more in the albumin-treated patients $(P=0.03)$ [30]; these patients also had a less positive fluid balance $(P=0.04)$. There was also a beneficial effect on cumulative calorie intake during the first week, suggesting that albumin may have helped decrease intestinal edema.

The effects of albumin administration may also depend on the simultaneous use of diuretics to prevent an albumin infusion-induced increase in hydrostatic pressure, which may increase (rather than decrease) edema formation. Some studies have suggested that the concurrent use of albumin may increase furosemide-induced diuresis in hypooncotic patients with acute respiratory distress syndrome/acute lung injury $[65,66]$ and cirrhosis-induced ascites [67], although not in all critically ill patients [68]; whether this strategy has any effect on patient-centered clinical outcomes is unclear.
In 1999 Sort and colleagues published the results of a RCT in 126 patients with cirrhosis and spontaneous bacterial peritonitis comparing treatment with intravenous cefotaxime or cefotaxime plus intravenous albumin for plasma volume expansion [52]. Renal impairment developed in fewer patients in the patients who received albumin $(P=0.002)$ and these patients also had reduced hospital and 3-month mortality rates (both $P=0.01$ ). A more recent RCT reported beneficial effects of albumin plus antibiotic on renal and circulatory function in 110 patients with cirrhosis and infections other than spontaneous bacterial peritonitis; treatment with albumin was an independent predictive factor of survival [69]. A meta-analysis of 16 RCTs also suggested that albumin use was associated with a significant reduction in mortality (odds ratio, $0.46 ; 95 \% \mathrm{CI}, 0.25$ to 0.86 ) and renal impairment (odds ratio, 0.34 ; $95 \% \mathrm{CI}, 0.15$ to 0.75 ) in patients with cirrhosis and any infection [70]. Two small RCTs have also demonstrated improved renal function in patients with cirrhosis and hepatorenal syndrome treated with albumin and terlipressin [71,72].

\section{Recent randomized controlled trial results}

Following the results of the SAFE study suggesting a benefit of albumin administration in patients with sepsis, several groups designed RCTs to further evaluate albumin use in this specific group of patients.

In the ALBIOS study, conducted in 100 ICUs in Italy [62], 1,818 patients with severe sepsis or septic shock were randomized either to receive $300 \mathrm{ml}$ of $20 \%$ albumin plus crystalloid or to receive crystalloid alone initially to achieve the target resuscitation goals of the early goal-directed therapy protocol used by Rivers and colleagues [73]. Over the subsequent 28 days, albumin infusions were adjusted to maintain serum albumin $\geq 30 \mathrm{~g} / \mathrm{l}$; crystalloid solutions were given when considered clinically indicated by the attending physician. More patients in the albumin group than in the crystalloid group reached the target mean arterial pressure within 6 hours after randomization $(86 \%$ versus $82.5 \%, P=$ 0.04 ), and during the first 7 days the mean arterial pressure was higher and the net fluid balance lower in the albumin group than in the crystalloid group [62], despite similar amounts of fluid being administered to the two groups. There were, however, no overall differences in 28-day mortality rates (32\% albumin vs $32 \%$ crystalloid; relative risk in the albumin group, $1.00 ; 95 \% \mathrm{CI}, 0.87$ to $1.14 ; P=0.94$ ) or 90-day mortality rates ( $41 \%$ albumin vs $44 \%$ crystalloid; relative risk, $0.94 ; 95 \% \mathrm{CI}, 0.85$ to $1.05 ; P=0.29$ ) between the groups. Of the 1,818 patients, $579(31.8 \%)$ were randomized within 6 hours and 1,239 (68.2\%) more than 6 hours after meeting the clinical criteria for severe sepsis; there were no significant differences in outcomes according to the interval between meeting clinical criteria and randomization. In the subgroup of patients with septic 
shock at enrollment $(n=1,121)$, however, those who received albumin had significantly lower 90-day mortality rates than those who received saline (44\% versus $50 \%$; relative risk, $0.87 ; 95 \% \mathrm{CI}, 0.77$ to $0.99 ; P=0.03$ ) [62].

In the multicenter EARSS study in France, so far published only in abstract form [61], 798 patients with septic shock of less than 6 hours duration were randomized to receive 100 $\mathrm{ml}$ of $20 \%$ albumin or $100 \mathrm{ml}$ of $0.9 \%$ saline every 8 hours for 3 days. Almost all patients had severe hypoalbuminemia at study inclusion. There were no significant differences in mortality rates between the two groups (24.1 vs $26.3 \%$ ).

\section{Where next?}

Having briefly reviewed the background to the albumin story so far, where are we left? Who, if anyone, should be given albumin? Some answers will be provided from further analysis of the results from recent and ongoing studies, but in the meantime we believe there are six key questions that need answering.

\section{Resuscitation versus supplementation (medication)?}

Initially considered largely as an acute resuscitation fluid for its beneficial short-term effects on COP and blood volume, recognition of the adverse outcomes associated with hypoalbuminemia and new knowledge about vascular barrier functioning has led to an increased interest in use of albumin solutions as a supplement to correct and maintain albumin levels. Nevertheless, it is difficult to separate volume effects from the effects of maintenance of serum albumin - particularly in critically ill patients, many of whom are hypoalbuminemic and in whom it is difficult to clearly relate the timing of interventions to the onset of disease. Thus, most studies of albumin administration actually combine a degree of resuscitation with a degree of supplementation/maintenance of serum albumin. As a resuscitation fluid, the major benefit of albumin will be from its impact on COP, resulting in a short-term increase in intravascular volume. As supplementation, effects on COP are also important, potentially reducing the risk of interstitial edema, but some of albumin's other actions, such as transport and antioxidant effects, may also become important.

Efforts to substitute synthetic colloids for albumin as part of perioperative fluid therapy have not been very successful. Hydroxyethylstarch solutions can persist for long durations in the skin, the liver and, most importantly, the kidney [74], with a potential risk of renal failure and even increased mortality rates in septic patients [75]. Gelatin solutions have been less well studied, in part because they are not available in the United States, and their persistence is quite short.

\section{Which concentration of albumin solution?}

Albumin solutions are available in a variety of concentrations, mainly 20 to $25 \%$ or 4 to $5 \%$, and which concentration should be used has generated some debate. Direct blood volume measurements in humans have revealed that the intravascular volume effect of isooncotic preparations of human albumin solutions is much higher than that of crystalloids ( $>80 \%$ vs $<20 \%$ ) [76]. However, the albumin concentration chosen largely depends on whether other fluids, especially crystalloids, are administered simultaneously - a $20 \%$ (20 g in $100 \mathrm{ml}$ ) albumin solution given simultaneously with $500 \mathrm{ml}$ of normal saline solution is equivalent to a 3.3\% (20/600) albumin solution. Nevertheless, hyperoncotic albumin may be a better choice if edema is already present [77], avoiding excessive sodium and chloride loads and their attendant complications [78].

\section{Which dose of albumin?}

Determining the ideal dose or volume of albumin that should be used is difficult. Early physiological studies demonstrated that administration of $5 \%$ albumin to septic patients expanded the plasma volume by an amount equivalent to the volume infused [79]. Different studies have used different doses, and perhaps the dose should be adjusted according to a target serum albumin concentration, as in the ALBIOS study [62]. The dose chosen by Mira and colleagues in the EARSS study (100 $\mathrm{ml}$ of $20 \%$ albumin 8 hourly for 3 days) achieved an increase in serum albumin to 25 to $29 \mathrm{~g} / \mathrm{l}$ [61], raising the possibility that the albumin dose used may have been too low to show definite benefit - although this increase was similar to that reported in the SAFE study subgroup analysis of patients with sepsis, in whom a benefit was reported [54].

\section{Should albumin infusions target albumin levels?}

The need to make decisions as to whether or not a particular patient should receive albumin based on their albumin level is related to whether the considered use is targeted as resuscitation or supplementation. Most patients requiring resuscitation fluids in the ICU are hypoalbuminemic and, as mentioned earlier, the fluid will be given largely for its effects on COP - that is, limiting edema formation - provided that the hydrostatic pressure does not increase excessively. In such patients, monitoring the albumin concentration is probably of little value.

In more prolonged administration as supplementation, however, serum albumin levels may be a useful guide to ongoing needs, in combination with disease severity, hemodynamic status, and nutritional status; just as an arbitrary cutoff hemoglobin concentration should not be used to define absolute need for blood transfusion in all patients, so a specific serum albumin threshold for albumin administration is unlikely to be relevant to all. The meta-analysis of nine prospective controlled trials on correcting hypoalbuminemia in acutely ill patients mentioned earlier suggested that complication rates were reduced in patients who achieved serum albumin concentrations $>30$ 
g/l after albumin administration [5]. As a result, the ALBIOS study protocol stipulated that albumin administration should be titrated to maintain serum albumin $\geq 30$ g/l [62]. Albumin levels were measured on a daily basis and 200 or $300 \mathrm{ml}$ of $20 \%$ albumin were administered in patients with albumin levels between 25 and $30 \mathrm{~g} / \mathrm{l}$ or $<25$ g/l, respectively. Following the time course of albumin levels, especially in response to an albumin infusion, may be more valuable than a single albumin level, but optimal albumin levels during critical illness are not clearly defined.

\section{What type of albumin preparation?}

Currently available human albumin solutions are developed using various techniques, such that the various commercially available albumin solutions may differ in protein content and composition, binding capacity, metal ion content, antioxidant properties, charge, capacity to bind drugs, and so forth $[80,81]$. This is a difficult topic to evaluate because there are few data available about the precise composition of the different albumin solutions and whether or how this may impact on its clinical properties $[81,82]$, but the differences may help explain some of the different study results. One study comparing six different commercially available preparations of albumin with serum albumin from healthy volunteers reported large differences between the solutions, particularly in terms of the presence of oxidized cysteine 34 ( $23 \%$ in human volunteer albumin vs 54 to $60 \%$ in commercial preparations) [81], which may influence the properties and hence the clinical impact of albumin solutions [82]. Precise compositions of albumin solution should be clearly identified in future study reports.

\section{Is albumin cost-effective?}

Albumin solutions have a good safety record [83]. The large SAFE study reported that $4 \%$ albumin was as safe as normal saline in a heterogeneous group of ICU patients [49] and meta-analyses have noted that albumin has a better safety profile than other colloid solutions $[84,85]$. Reports of adverse events, including anticoagulant and allergic effects and transmission of microorganisms, are rare. In a study evaluating adverse event reporting between 1998 and 2000, the incidence of all reported serious nonfatal and fatal adverse events was just 5 per million doses, and no patient death was classified as probably related to albumin administration [83].

Albumin is, however, more costly than all other resuscitation fluids, although prices have decreased relative to other fluids over the last 10 years. Nevertheless, if shown to reduce morbidity and mortality even by a small amount, it is likely that the cost-effectiveness ratio would favor albumin because so many ICU interventions are very costly. There have been very few cost- effectiveness evaluations of albumin use in the ICU. Guidet and colleagues assessed the cost-effectiveness of albumin as given in the SAFE study on patients with severe sepsis and septic shock admitted to one of 35 French ICUs [86]. Based on a presumed 4.6\% reduction in mortality associated with albumin therapy (as shown in the SAFE study), 513 lives were saved among the 11,137 patients included, with an estimated life expectancy for each life saved of 9.8 years. The cost per life saved was estimated at $€ 6,037$ and the cost per life-year saved as $€ 617$. The authors therefore concluded that albumin administration was a cost-effective intervention in patients with severe sepsis or septic shock [86]. Most recently, a cost-effectiveness analysis in severe sepsis and septic shock using an advanced Bayesian approach observed life-years gained with albumin relative to crystalloid therapy, and concluded that albumin may be the most cost-effective intravenous solution in this patient population [87].

\section{Recommendations and conclusions}

Many changes within intensive care medicine have come as the result of the realization that traditional practices once thought to be therapeutic were in fact detrimental [88]. Human albumin solutions have been available for almost 60 years and provide effective resuscitation with less fluid required than for crystalloid solutions; for many years, however, albumin was widely and perhaps nondiscriminantly used as a resuscitation fluid with little realization that it may not be appropriate in all patients. Although criticized for its methodology and the heterogeneity of the studies included, the 1998 Cochrane meta-analysis brought this possibility to the attention of the wider community and stimulated the conduct of large, multicenter RCTs [2]. As the results of these studies become available, the role of albumin in today's critical care unit is becoming clearer and several recommendations can be made:

- Albumin administration, although unlikely to cause harm in most patients, is not necessary in all critically ill patients and should be reserved for use in specific groups of patients in whom there is evidence of benefit.

- A hypotonic albumin solution should be avoided as a resuscitation fluid in patients with traumatic brain injury, based on the results of the SAFE subgroup analysis [55].

- There is now enough evidence - albeit largely from subgroup analyses - and plausible biological rationale to support use of albumin in patients with septic shock when a colloid is considered [54,62].

- Albumin administration should be considered in patients with cirrhosis and spontaneous bacterial peritonitis [52], but possibly also other infections 
[69,70]; in hypooncotic patients with acute respiratory distress syndrome $[65,66]$; and also in patients with cirrhosis and type 1 hepatorenal syndrome [89].

Future research should be focused on patients who are most likely to benefit from albumin administration in whom the evidence is inadequate or controversial because of conflicting study results. In addition to observational cohort studies and RCTs focusing on specific patient groups, mechanistic studies are necessary to further elucidate the molecular and physiologic rationale for the beneficial effects of albumin and explore how albumin's pleiotropic actions may be important in specific groups of critically ill patients. Such studies also need to better elucidate the mechanisms of development of hypoalbuminemia. Studies also need to clarify issues of dosage and appropriate targets and whether different albumin solutions have unique differential effects on patients' responses and outcomes to albumin administration. The effects of albumin infusions on drug (especially antimicrobial) dosing also need clarification.

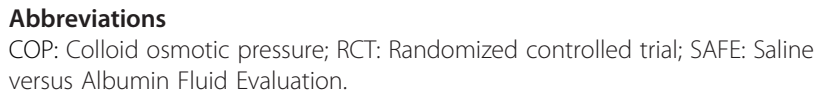

\section{Competing interests}

J-LV has no conflicts of interest related to this article. JAR reports patents owned by the University of British Columbia that are related to the genetics of sepsis and its treatment; the University of British Columbia has also submitted a patent related to the use of vasopressin in septic shock. JAR is an inventor on these patents. JAR also reports receiving consulting fees from Ferring Pharmaceuticals (which manufactures vasopressin and is developing selepressin), Grifols (which sells albumin), Trius Pharmaceuticals (which is developing antibiotics), and Sirius Genomics Inc.; and reports having received grant support from Sirius Genomics, Ferring Pharmaceuticals, and Astra Zeneca that is provided to and administered by the University of British Columbia. MJ has held lectures for B. Braun, Fresenius Kabi, Serumwerk Bernburg, Baxter and Grifols; has received unrestricted research grants from Fresenius Kabi, CSL Behring, Serumwerk Bernburg and Grifols; and is a member of the Grifols AAB. GM serves on advisory boards for Grifols and CSL Behring, and his institution has received research grant support from Baxter Healthcare. BG has received honoraria for lectures from Fresenius Kabi and LFB, and he is on the advisory board of Grifols and Fresenius Kabi. JW is a member of the Advisory Boards and an invited speaker for Baxter, Danone, Fresenius-Kabi, Grifols, and Nestlé. RFR has received honoraria for lectures from Pfizer, Astellas and Grupo Ferrer, and is on the Advisory boards of Grifols, Bellco and Grupo Ferrer. SAM has received speaker's honoraria from Fresenius Kabi. LG is on the Advisory board of Grifols and has received speaker's honoraria from $\mathrm{KCl}$, B. Braun, Baxter, Grifols, and Kedrion.

\section{Acknowledgements}

This report was sponsored by an unrestricted educational grant from Grifols SA (Barcelona, Spain). Grifols had no input into the contents of the text or the decision to publish.

\section{Author details}

${ }^{1}$ Department of Intensive Care, Erasme Hospital, Université libre de Bruxelles, route de Lennik 808, 1070 Brussels, Belgium. ${ }^{2}$ Center for Heart Lung Innovation and Critical Care Medicine, University of British Columbia and St. Paul's Hospital, Vancouver, Canada V6Z BC. ${ }^{3}$ Department of Anaesthesiology, University Hospital Munich, Nussbaumstraße 20, 80336 Munich, Germany. ${ }^{4}$ Department of Medicine, Division of Pulmonary, Allergy and Critical Care, Emory University School of Medicine, Atlanta, GA 30303, USA. ${ }^{5}$ Service Réanimation Médicale, Hôpital Saint Antoine, Universitaires Est Parisien, Paris, France. ${ }^{6}$ Sorbonne Universités, UPMC Université Paris 06, UMR-S 1136, Institut
Pierre Louis d'Epidémiologie et de Santé Publique, F-75013 Paris, France. ${ }^{7}$ Department of Anesthesiology \& Intensive Care Medicine, Karolinska University Hospital, Huddinge, 14186 Stockholm, Sweden. ${ }^{8}$ Servei de Medicina Intensiva, Hospital Universitari Mútua Terrassa, Universitat de Barcelona, CIBER Enfermedades Respiratorias, 08221 Terrassa, Barcelona, Spain. ${ }^{9}$ Department of Anesthesia and Pain Management, Toronto General Hospital, University of Toronto, Toronto, Ontario, Canada M5G 2C4. ${ }^{10}$ Dipartimento di Anestesia, Rianimazione (Intensiva e Subintensiva) e Terapia del Dolore, Fondazione IRCCS Ca' Granda - Ospedale Maggiore Policlinico, 20122 Milan, Italy.

Published: 16 Jul 2014

\section{References}

1. Ancell $\mathrm{H}$ : Course of lectures on the physiology and pathology of the blood, and other animal fluids. Lancet 1839, 33:222-231.

2. Cochrane Injuries Group Albumin Reviewers: Human albumin administration in critically ill patients: systematic review of randomised controlled trials. BMJ 1998, 317:235-240.

3. Vincent $\mathrm{J}$ : Relevance of albumin in modern critical care medicine. Best Pract Res Clin Anaesthesiol 2009, 23:183-191.

4. Finfer S, Bellomo R, McEvoy S, Lo SK, Myburgh J, Neal B, Norton R: Effect of baseline serum albumin concentration on outcome of resuscitation with albumin or saline in patients in intensive care units: analysis of data from the saline versus albumin fluid evaluation (SAFE) study. BMJ 2006, 333:1044.

5. Vincent $J$, Dubois MJ, Navickis RJ, Wilkes MM: Hypoalbuminemia in acute illness: is there a rationale for intervention? A meta-analysis of cohort studies and controlled trials. Ann Surg 2003, 237:319-334.

6. Laxenaire MC, Charpentier C, Feldman L: Anaphylactoid reactions to colloid plasma substitutes: incidence, risk factors, mechanisms. A French multicenter prospective study. Ann Fr Anesth Reanim 1994, 13:301-310

7. McClelland DB: Safety of human albumin as a constituent of biologic therapeutic products. Transfusion 1998, 38:690-699.

8. American Thoracic Society: Evidence-based colloid use in the critically ill: American Thoracic Society Consensus Statement. Am J Respir Crit Care Med 2004, 170:1247-1259.

9. Peters T: All About Albumin. San Diego: Academic Press; 1995

10. Fanali G, di Masi A, Trezza V, Marino M, Fasano M, Ascenzi P: Human serum albumin: from bench to bedside. Mol Aspects Med 2012, 33:209-290.

11. The Bovine and Human Albumin Programs. [http://history.amedd.army. mil/booksdocs/wwii/blood/chapter12.htm].

12. Matejtschuk $\mathrm{P}$, Dash $\mathrm{CH}$, Gascoigne EW: Production of human albumin solution: a continually developing colloid. Br J Anaesth 2000, 85:887-895.

13. Nicholson JP, Wolmarans MR, Park GR: The role of albumin in critical illness. Br J Anaesth 2000, 85:599-610.

14. Fleck A, Raines G, Hawker F, Trotter J, Wallace PI, Ledingham IM, Calman KC: Increased vascular permeability: a major cause of hypoalbuminaemia in disease and injury. Lancet 1985, 1:781-784.

15. Margarson MP, Soni N: Serum albumin: touchstone or totem? Anaesthesia 1998, 53:789-803.

16. Woodcock TE, Woodcock TM: Revised Starling equation and the glycocalyx model of transvascular fluid exchange: an improved paradigm for prescribing intravenous fluid therapy. Br J Anaesth 2012, 108:384-394.

17. Jacob M, Bruegger D, Rehm M, Stoeckelhuber M, Welsch U, Conzen P, Becker BF: The endothelial glycocalyx affords compatibility of Starling's principle and high cardiac interstitial albumin levels. Cardiovasc Res 2007, 73:575-586.

18. Adamson RH, Lenz JF, Zhang X, Adamson GN, Weinbaum S, Curry FE: Oncotic pressures opposing filtration across non-fenestrated rat microvessels. J Physiol 2004, 557:889-907.

19. Jacob M, Bruegger D, Rehm M, Welsch U, Conzen P, Becker BF: Contrasting effects of colloid and crystalloid resuscitation fluids on cardiac vascular permeability. Anesthesiology 2006, 104:1223-1231.

20. Pries AR, Secomb TW, Gaehtgens P: The endothelial surface layer. Pflugers Arch 2000, 440:653-666. 
21. Zausig YA, Chappell D, Becker BF, Potschka D, Busse H, Nixdorf K, Bitzinger D, Jacob B, Jacob M: The impact of crystalloidal and colloidal infusion preparations on coronary vascular integrity, interstitial oedema and cardiac performance in isolated hearts. Crit Care 2013, 17:R203.

22. Chappell D, Westphal M, Jacob M: The impact of the glycocalyx on microcirculatory oxygen distribution in critical illness. Curr Opin Anaesthesiol 2009, 22:155-162.

23. Jacob M, Chappell D: Reappraising Starling: the physiology of the microcirculation. Curr Opin Crit Care 2013, 19:282-289.

24. Roche $M$, Rondeau $P$, Singh NR, Tarnus E, Bourdon E: The antioxidant properties of serum albumin. FEBS Lett 2008, 582:1783-1787.

25. Oettl K, Stauber RE: Physiological and pathological changes in the redox state of human serum albumin critically influence its binding properties. Br J Pharmacol 2007, 151:580-590

26. Taverna M, Marie AL, Mira JP, Guidet B: Specific antioxidant properties of human serum albumin. Ann Intensive Care 2013, 3:4.

27. Ulldemolins M, Roberts JA, Rello J, Paterson DL, Lipman J: The effects of hypoalbuminaemia on optimizing antibacterial dosing in critically ill patients. Clin Pharmacokinet 2011, 50:99-110.

28. Figge J, Rossing $\mathrm{TH}$, Fencl $\mathrm{V}$ : The role of serum proteins in acid-base equilibria. J Lab Clin Med 1991, 117:453-467.

29. Jorgensen KA, Stoffersen E: On the inhibitory effect of albumin on platelet aggregation. Thromb Res 1980, 17:13-18.

30. Dubois MJ, Orellana-Jimenez C, Melot C, De Backer D, Berre J, Leeman M, Brimioulle S, Appoloni O, Creteur J, Vincent JL: Albumin administration improves organ function in critically ill hypoalbuminemic patients: a prospective, randomized, controlled, pilot study. Crit Care Med 2006, 34:2536-2540

31. Redelmeier DA: New thinking about postoperative hypoalbuminemia: a hypothesis of occult protein-losing enteropathy. Open Med 2009, 3:e215-e219.

32. Caironi $P$, Gattinoni $L$ : The clinical use of albumin: the point of view of a specialist in intensive care. Blood Transfus 2009, 7:259-267.

33. Moshage HJ, Janssen JA, Franssen JH, Hafkenscheid JC, Yap SH: Study of the molecular mechanism of decreased liver synthesis of albumin in inflammation. J Clin Invest 1987, 79:1635-1641.

34. Barle H, Hammarqvist F, Westman B, Klaude M, Rooyackers O, Garlick PJ, Wernerman J: Synthesis rates of total liver protein and albumin are both increased in patients with an acute inflammatory response. Clin $\mathrm{SCi}$ (Lond) 2006, 110:93-99.

35. Serra R, Caroleo S, Buffone G, Lugara M, Molinari V, Tropea F, Amantea B, de Franciscis S: Low serum albumin level as an independent risk factor for the onset of pressure ulcers in intensive care unit patients. Int Wound J 2012, doi: 10.1111/iwj.12004.

36. Al-Subaie N, Reynolds T, Myers A, Sunderland R, Rhodes A, Grounds RM, Hall GM: C-reactive protein as a predictor of outcome after discharge from the intensive care: a prospective observational study. Br J Anaesth 2010, 105:318-325.

37. Wiedermann CJ, Wiedermann W, Joannidis M: Hypoalbuminemia and acute kidney injury: a meta-analysis of observational clinical studies. Intensive Care Med 2010, 36:1657-1665.

38. Lee EH, Baek SH, Chin JH, Choi DK, Son HJ, Kim WJ, Hahm KD, Sim JY, Choi IC: Preoperative hypoalbuminemia is a major risk factor for acute kidney injury following off-pump coronary artery bypass surgery. Intensive Care Med 2012, 38:1478-1486.

39. Lyons O, Whelan B, Bennett K, O'Riordan D, Silke B: Serum albumin as an outcome predictor in hospital emergency medical admissions. Eur $\lrcorner$ Intern Med 2010, 21:17-20.

40. Bernard F, Al-Tamimi YZ, Chatfield D, Lynch AG, Matta BF, Menon DK: Serum albumin level as a predictor of outcome in traumatic brain injury: potential for treatment. J Trauma 2008, 64:872-875.

41. Namendys-Silva SA, Gonzalez-Herrera MO, Texcocano-Becerra J, HerreraGomez A: Hypoalbuminemia in critically ill patients with cancer: incidence and mortality. Am J Hosp Palliat Care 2011, 28:253-257.

42. de la Cruz Kl, Bakaeen FG, Wang XL, Huh J, LeMaire SA, Coselli JS, Chu D: Hypoalbuminemia and long-term survival after coronary artery bypass: a propensity score analysis. Ann Thorac Surg 2011, 91:671-675.

43. Artero A, Zaragoza R, Camarena JJ, Sancho S, Gonzalez R, Nogueira JM: Prognostic factors of mortality in patients with community-acquired bloodstream infection with severe sepsis and septic shock. J Crit Care 2010, 25:276-281.
44. Ranzani OT, Zampieri FG, Forte DN, Azevedo LC, Park M: C-reactive protein/ albumin ratio predicts 90 -day mortality of septic patients. PLoS One 2013, 8:e59321.

45. Gibbs J, Cull W, Henderson W, Daley J, Hur K, Khuri SF: Preoperative serum albumin level as a predictor of operative mortality and morbidity: results from the National VA Surgical Risk Study. Arch Surg 1999, 134:36-42.

46. Skillman JJ, Restall DS, Salzman EW: Randomized trial of albumin vs. electrolyte solutions during abdominal aortic operations. Surgery 1975, 78:291-303.

47. Roberts I, Edwards P, McLelland B: More on albumin. Use of human albumin in UK fell substantially when systematic review was published. BMJ 1999, 318:1214-1215.

48. CSM Expert Working Party: The safety of human albumin. Curr Probl Pharmacovigilance 1999, 25:11.

49. Finfer S, Bellomo R, Boyce N, French J, Myburgh J, Norton R: A comparison of albumin and saline for fluid resuscitation in the intensive care unit. N Engl J Med 2004, 350:2247-2256.

50. Woodruff LM, Gibson ST: The clinical evaluation of human albumin. US Naval Med Bull 1942, 40:791-796.

51. Dear Doctor Letter - Albumin Use in Seriously III Patients. [http://www. fda.gov/BiologicsBloodVaccines/SafetyAvailability/ucm105919.htm]

52. Sort $P$, Navasa $M$, Arroyo $V$, Aldeguer $X$, Planas R, Ruiz-del-Arbol L, Castells $L$, Vargas $V$, Soriano G, Guevara M, Gines $P$, Rodes J: Effect of intravenous albumin on renal impairment and mortality in patients with cirrhosis and spontaneous bacterial peritonitis. N Engl J Med 1999, 341:403-409.

53. Wilkes MM, Navickis RJ: Patient survival after human albumin administration. A meta-analysis of randomized, controlled trials. Ann Intern Med 2001, 135:149-164.

54. Finfer S, McEvoy S, Bellomo R, McArthur C, Myburgh J, Norton R: Impact of albumin compared to saline on organ function and mortality of patients with severe sepsis. Intensive Care Med 2011, 37:86-96.

55. Myburgh J, Cooper DJ, Finfer S, Bellomo R, Norton R, Bishop N, Kai LS, Vallance S: Saline or albumin for fluid resuscitation in patients with traumatic brain injury. N Engl J Med 2007, 357:874-884.

56. Safety of Albumin Administration in Critically III Patients. [http://www.fda. gov/BiologicsBloodVaccines/SafetyAvailability/BloodSafety/ucm095539.htm].

57. Vincent JL, Sakr Y, Reinhart K, Sprung CL, Gerlach H, Ranieri VM: Is albumin administration in the acutely ill associated with increased mortality? Results of the SOAP study. Crit Care 2005, 9:R745-R754.

58. Delaney AP, Dan A, McCaffrey J, Finfer S: The role of albumin as a resuscitation fluid for patients with sepsis: a systematic review and meta-analysis. Crit Care Med 2011, 39:386-391.

59. Reinhart K, Perner A, Sprung CL, Jaeschke R, Schortgen F, Johan Groeneveld $A B$, Beale R, Hartog CS: Consensus statement of the ESICM task force on colloid volume therapy in critically ill patients. Intensive Care Med 2012 38:368-383.

60. Dellinger RP, Levy MM, Rhodes A, Annane D, Gerlach H, Opal SM, Sevransky JE, Sprung CL, Douglas IS, Jaeschke R, Osborn TM, Nunnally ME, Townsend SR, Reinhart K, Kleinpell RM, Angus DC, Deutschman CS, Machado FR, Rubenfeld GD, Webb SA, Beale RJ, Vincent JL, Moreno R: Surviving sepsis campaign: international guidelines for management of severe sepsis and septic shock: 2012. Crit Care Med 2013, 41:580-637.

61. Charpentier J, Mira JP, EARSS Study Group: Efficacy and tolerance of hyperoncotic albumin administration in septic shock patients: the EARSS study [abstract]. Intensive Care Med 2011, 37(Suppl 2):S115-0438.

62. Caironi P, Tognoni G, Masson S, Fumagalli R, Pesenti A, Romero M, Fanizza C, Caspani L, Faenza S, Grasselli G, lapichino G, Antonelli M, Parrini V, Fiore $\mathrm{G}$, Latini R, Gattinoni L: Albumin replacement in patients with severe sepsis or septic shock. N Engl J Med 2014, 370:1412-1421.

63. Cooper DJ, Myburgh J, Heritier S, Finfer S, Bellomo R, Billot L, Murray L, Vallance S: Albumin resuscitation for traumatic brain injury: is intracranial hypertension the cause of increased mortality? J Neurotrauma 2013, 30:512-518

64. Van Aken HK, Kampmeier TG, Ertmer C, Westphal M: Fluid resuscitation in patients with traumatic brain injury: what is a SAFE approach? Curr Opin Anaesthesiol 2012, 25:563-565.

65. Martin GS, Mangialardi RJ, Wheeler AP, Dupont WD, Morris JA, Bernard GR: Albumin and furosemide therapy in hypoproteinemic patients with acute lung injury. Crit Care Med 2002, 30:2175-2182.

66. Martin GS, Moss M, Wheeler AP, Mealer M, Morris JA, Bernard GR: A randomized, controlled trial of furosemide with or without albumin in hypoproteinemic patients with acute lung injury. Crit Care Med 2005 33:1681-1687 
67. Gentilini P, Casini-Raggi V, Di Fiore G, Romanelli RG, Buzzelli G, Pinzani M, La Villa G, Laffi G: Albumin improves the response to diuretics in patients with cirrhosis and ascites: results of a randomized, controlled trial. J Hepatol 1999, 30:639-645.

68. Doungngern T, Huckleberry Y, Bloom JW, Erstad B: Effect of albumin on diuretic response to furosemide in patients with hypoalbuminemia. Am J Crit Care 2012, 21:280-286.

69. Guevara M, Terra C, Nazar A, Sola E, Fernandez J, Pavesi M, Arroyo V, Gines $P$ : Albumin for bacterial infections other than spontaneous bacterial peritonitis in cirrhosis. A randomized, controlled study. J Hepatol 2012, 57:759-765

70. Kwok CS, Krupa L, Mahtani A, Kaye D, Rushbrook SM, Phillips MG, Gelson W: Albumin reduces paracentesis-induced circulatory dysfunction and reduces death and renal impairment among patients with cirrhosis and infection: a systematic review and meta-analysis. Biomed Res Int 2013, 2013:295153.

71. Martin-Llahi M, Pepin MN, Guevara M, Diaz F, Torre A, Monescillo A, Soriano G, Terra C, Fabrega E, Arroyo V, Rodes J, Gines P: Terlipressin and albumin vs albumin in patients with cirrhosis and hepatorenal syndrome: a randomized study. Gastroenterology 2008, 134:1352-1359.

72. Neri S, Pulvirenti D, Malaguarnera M, Cosimo BM, Bertino G, Ignaccolo L, Siringo S, Castellino P: Terlipressin and albumin in patients with cirrhosis and type I hepatorenal syndrome. Dig Dis Sci 2008, 53:830-835.

73. Rivers E, Nguyen B, Havstad S, Ressler J, Muzzin A, Knoblich B, Peterson E, Tomlanovich M: Early goal-directed therapy in the treatment of severe sepsis and septic shock. N Engl J Med 2001, 345:1368-1377.

74. Wiedermann CJ, Joannidis M: Accumulation of hydroxyethyl starch in human and animal tissues: a systematic review. Intensive Care Med 2014, 40:160-170.

75. Perner A, Haase N, Guttormsen AB, Tenhunen J, Klemenzson G, Aneman A Madsen KR, Moller MH, Elkjaer JM, Poulsen LM, Bendtsen A, Winding R, Steensen M, Berezowicz P, Soe-Jensen P, Bestle M, Strand K, Wiis J, White JO, Thornberg KJ, Quist L, Nielsen J, Andersen LH, Holst LB, Thormar K, Kjaeldgaard AL, Fabritius ML, Mondrup F, Pott FC, Moller TP, et al: Hydroxyethyl starch 130/0.42 versus Ringer's acetate in severe sepsis. N Engl J Med 2012, 367:124-134.

76. Rehm M, Orth V, Kreimeier U, Thiel M, Haller M, Brechtelsbauer H, Finsterer U: Changes in intravascular volume during acute normovolemic hemodilution and intraoperative retransfusion in patients with radical hysterectomy. Anesthesiology 2000, 92:657-664.

77. Jacob M, Chappell D, Hofmann-Kiefer K, Helfen T, Schuelke A, Jacob B, Burges A, Conzen $P$, Rehm M: The intravascular volume effect of Ringer's lactate is below 20\%: a prospective study in humans. Crit Care 2012, 16:R86.

78. Yunos NM, Bellomo R, Hegarty C, Story D, Ho L, Bailey M: Association between a chloride-liberal vs chloride-restrictive intravenous fluid administration strategy and kidney injury in critically ill adults. JAMA 2012, 308:1566-1572.

79. Ernest D, Belzberg AS, Dodek PM: Distribution of normal saline and 5\% albumin infusions in septic patients. Crit Care Med 1999, 27:46-50.

80. Farrugia A: Albumin usage in clinical medicine: tradition or therapeutic? Transfus Med Rev 2010, 24:53-63.

81. Bar-Or D, Bar-Or R, Rael LT, Gardner DK, Slone DS, Craun ML: Heterogeneity and oxidation status of commercial human albumin preparations in clinical use. Crit Care Med 2005, 33:1638-1641.

82. Martin GS: Pharmacological aspects of albumin as a niche product in the intensive care unit. Crit Care Med 2005, 33:1667-1669.

83. Vincent $J$ L, Wilkes MM, Navickis RJ: Safety of human albumin - serious adverse events reported worldwide in 1998-2000. Br J Anaesth 2003, 91:625-630

84. Barron ME, Wilkes MM, Navickis RJ: A systematic review of the comparative safety of colloids. Arch Surg 2004, 139:552-563.

85. Groeneveld AB, Navickis RJ, Wilkes MM: Update on the comparative safety of colloids: a systematic review of clinical studies. Ann Surg 2011, 253:470-483.

86. Guidet B, Mosqueda GJ, Priol G, Aegerter P: The COASST study: cost-effectiveness of albumin in severe sepsis and septic shock. J Crit Care 2007, 22:197-203.

87. Farrugia A, Bansal M, Balboni S, Kimber MC, Martin GS, Cassar J: Choice of fluids in severe septic patients - a cost-effectiveness analysis informed by recent clinical trials. Rev Recent Clin Trials 2013, [Epub ahead of print].
88. Vincent JL, Fink MP, Marini JJ, Pinsky MR, Sibbald WJ, Singer M, Suter PM, Cook D, Pepe PE, Evans T: Intensive care and emergency medicine: progress over the past 25 years. Chest 2006, 129:1061-1067.

89. Salerno F, Gerbes A, Gines P, Wong F, Arroyo V: Diagnosis, prevention and treatment of hepatorenal syndrome in cirrhosis. Gut 2007, 56:1310-1318.

\section{$10.1186 /$ cc13991}

Cite this article as: Vincent et al:: Albumin administration in the acutely ill: what is new and where next?. Critical Care 2014, 18:231 